Document downloaded from:

http://hdl.handle.net/10251/61832

This paper must be cited as:

Ferrer Gisbert, CM.; Ferran Gozalvez, JJ.; Redón Santafé, M.; Ferrer-Gisbert, P.; SánchezRomero, F.; Torregrosa Soler, JB. (2013). A new photovoltaic floating cover system for water reservoirs. Renewable Energy. (60):63-70. doi:10.1016/j.renene.2013.04.007.

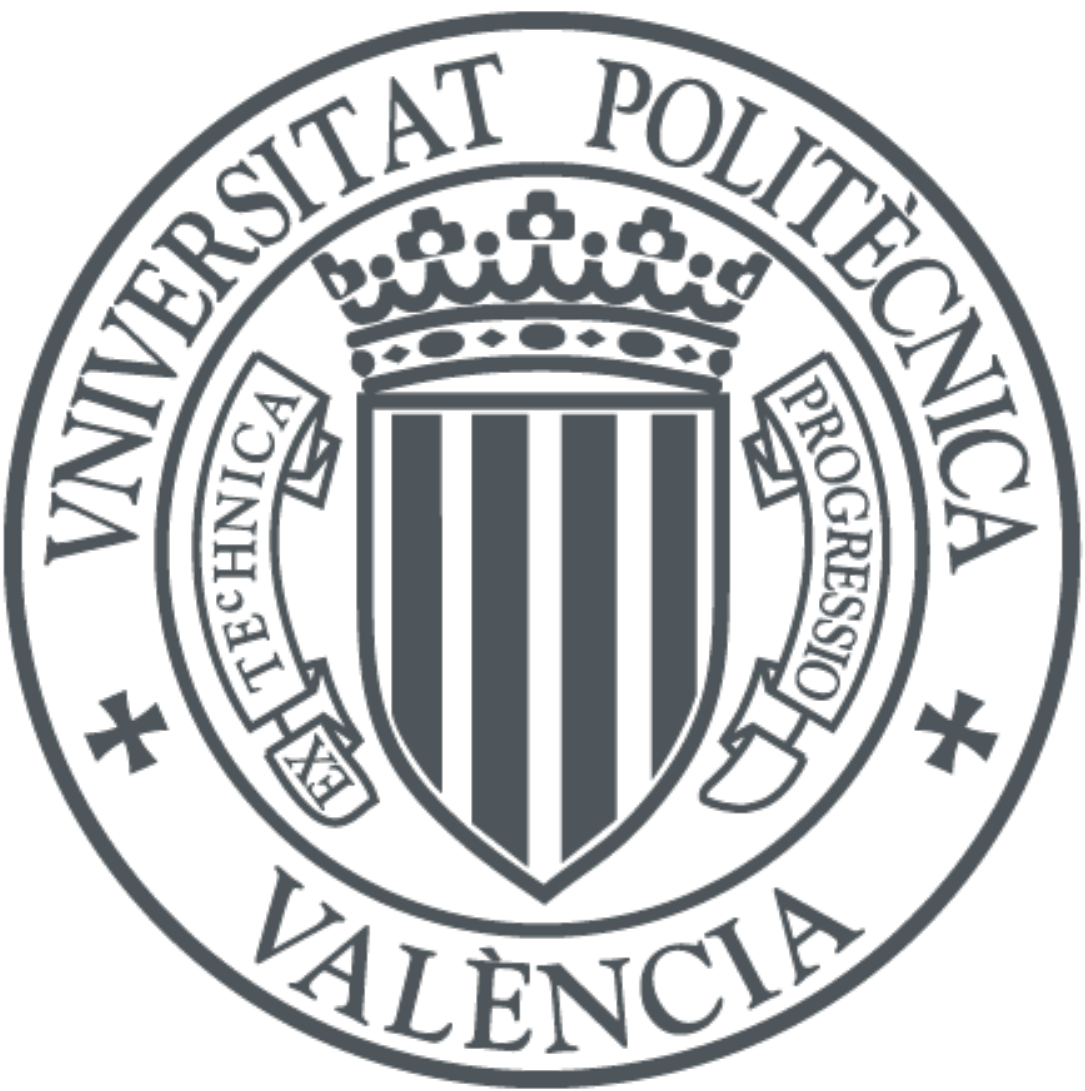

The final publication is available at

http://dx.doi.org/10.1016/j.renene.2013.04.007

Copyright Elsevier

Additional Information 


\title{
A NEW PHOTOVOLTAIC FLOATING COVER SYSTEM FOR WATER RESERVOIRS
}

\author{
Carlos Ferrer-Gisbert ${ }^{1}$, José J. Ferrán-Gozálvez ${ }^{1}$, Miguel Redón-Santafé ${ }^{1 *}$, Pablo \\ Ferrer-Gisbert ${ }^{2}$, Francisco J. Sánchez-Romero ${ }^{1}$, Juan Bautista Torregrosa-Soler ${ }^{1}$ \\ ${ }^{1}$ Universidad Politécnica de Valencia. Departamento de Ingeniería Rural y Agroalimentaria. Camino de \\ Vera s/n 46022 Valencia, Spain. \\ ${ }^{2}$ Universidad Politécnica de Valencia. Departamento de Proyectos de Ingeniería. Camino de Vera s/n \\ 46022 Valencia, Spain. \\ *Correspondance to: Miguel Redón-Santafé. Universidad Politécnica de Valencia. Departamento de \\ Ingeniería Rural y Agroalimentaria. Camino de Vera s/n 46022 VALENCIA, Spain \\ miresan@agf.upv.es
}

\begin{abstract}
This paper describes a new photovoltaic floating cover system for water reservoirs developed jointly by the company CELEMIN ENERGY and the Universidad Politécnica de Valencia. The system consists of polyethylene floating modules which, with the use of tension producing elements and elastic fasteners, are able to adapt to varying reservoir water levels.
\end{abstract}

A full-scale plant located near Alicante (Spain) was built in an agriculture reservoir to study the behaviour of the system. The top of the reservoir has a surface area of $4700 \mathrm{~m}^{2}$ but only $7 \%$ of such area has been covered with the fixed solar system.

The system also minimizes evaporation losses from water reservoirs.

Keywords: Photovoltaic floating cover, water reservoirs, evaporation water losses

\section{INTRODUCTION}

Nowadays, farmers' income is strongly affected by the electricity costs. High production costs, small farm size, competitive international markets and the water deficit are the main causes that characterize the difficult situation of the Spanish agriculture.

The demand for energy is to increase in the agriculture industry as a consequence of the greater use of the water resources and the modernization plans carried out in the last decades. The installation of more efficient irrigation systems has led to water savings; however, power consumption has grown because of increasing pumping needs and filter operations. So, although water efficiency has improved in the agriculture sector, electric power demand has increased substantially. Upward revisions of the electricity rates and uncertain future scenarios adversely affect the price of water.

The solutions to these problems come not only from setting special electricity rates for irrigation but also from improving the energy and water efficiency of the irrigation systems. Renewable energy sources emerge as a way to counter-balance such situations. 
The new irrigation plans involve the transformation of traditional systems into pressurized systems. In most cases, this modernization has demanded the construction of water reservoirs. Among the different storage systems available, earth reservoirs waterproofed with geomembranes are the most widely used solution.

In arid and semi-arid climates, water stored in reservoirs would be better managed if evaporation losses from the water surface were reduced.

In this sense, Bengoechea et al. [1] studied the water evaporation rate in agricultural water reservoirs in the south of Spain (Almeria) and estimated that water losses by evaporation in farms amounted to 17 percent. Martinez et al. [2] estimated water losses of $60 \mathrm{hm}^{3}$ for the Segura Basin (Murcia, Spain), which means more than $8 \%$ of the available water supply for irrigation purposes. Craig et al. [3] suggested that evaporation phenomena in agricultural reservoirs in Queensland (Australia) were the cause of a total water loss of $1,000 \mathrm{hm}^{3}$, i.e. about 40 percent of its total storage capacity. Gökbulak et al. [4] made similar studies from lakes and dams in Turkey and estimated potential water savings of more than $20 \%$.

The above results highlight that the evaporative losses from water storages at both the farm and the regional scales can be large. Thereby, the assessment of such losses and the development of evaporation mitigation techniques is crucial for preserving the limited water resources $[5,6,7]$.

In the last decades, several evaporation control products were developed to control evaporation losses from water reservoirs [8]. These products range from floating covers, modular covers, shade structures, chemical monolayer covers and biological and design methods. Craig et al. [3] highlighted the good performance of mechanical methods, either floating systems or suspended shade structures. The evaporation reduction achieved with such systems is around $80 \%$.

Moreover the use of floating covers provides other benefits like:

- lower filtering costs (by controlling sunlight and water temperature),

- much longer duration of the geomembranes,

- reduced silt accumulation.

But there is a lack of technical studies about cover systems for irrigation reservoirs. Although in Spain a standard for reservoir covers has been recently published [9], its scope is for systems based on geomembranes (not on floating ones) and it focuses on the execution process, not on system design.

However, latest trends show an increasing interest for developing membrane and spatial structures to minimise water evaporation $[10,11]$.

The Photovoltaic Floating Cover System (PFCS) described in this paper is the synergic response to the issues mentioned above and is highly innovative in today's agriculture sustainability. On the one hand, an evaporation mitigation technology is applied into agricultural water reservoirs. On the other hand, the production of clean energy is envisaged as a means of balance the electricity costs either exporting the electricity back to the grid or enabling to generate power for self-consumption [12].

The solution consists of a continuous platform placed above the water level by replicating a floating module which acts as the support of the photovoltaic panels. To our knowledge, no detailed studies assessing the performance of a photovoltaic covering system for reservoirs have been published to date. Also, a distinguishing 
element of the present system is that covers the whole area of the reservoir (bottom surface and upstream slope areas).

\section{KEY DESIGN ELEMENTS}

The primary purpose of the PFCS is to improve water and power efficiency of agricultural irrigation reservoirs as illustrated in Figure 1. The water surface is covered with a number of floating modules which are joined together by means of pins. Incident solar radiation is used to produce renewable energy. Additionally, properly designed reservoir cover systems prevent fluid loss due to evaporation and by blocking off sunlight they prevent algae bloom.

Figure 1: Water \& energy balance: a) Uncovered reservoir. b) Photovoltaic Floating Cover System

The key design factors affecting the performance of the system are:

- Good structural performance of the floating platform as a partially submerged body.

- Good structural behaviour of the reservoir and floating cover as a whole.

- Ability to adapt to varying reservoir water levels and reservoir layouts.

- Meeting the PV installation requirements.

- Minimizing in-situ work during construction and exploitation.

In summary, the primary purpose of the system is to meet the water requirements of the reservoir while maximizing power production.

\subsection{Suitability assessment of the reservoir layout}

Floating cover systems require site specific planning and design to be successful. Most reservoir designs are irregular in order to better fit land topography. Moreover, both the reservoir's walls and the different design layouts for the internal 3D geometry of the reservoir are highly variable. As a consequence, the geometry of the floating module has to be versatile enough to properly adapt to different internal geometries of the water reservoir.

\subsection{Geometry of the floating module}

The floating module's geometry was designed taking into account two main issues. First, the dimensions of the module must be adapted to commercial photovoltaic panels. Second, the modules must cover the maximum possible water surface to prevent water evaporation.

The solar issues under analysis were: photovoltaic panel dimensions and tilt angle, number of units to be installed, distance between panel rows to prevent shade effects and access ways to ease operational maintenance.

Several configurations and geometries of the floating module were studied before selecting the design presented in Figure 2, which comprises two 1.6x1.0m / $200 \mathrm{Wp}$ panels and a $0.5 \mathrm{~m}$ access way. 
Figure 2: Layout of the floating module

For the latitude of the field site (Agost, Alicante province, Spain), $30^{\circ}$ is the optimal tilt angle for the fix solar panels to maximize energy production. However the shade analysis for the prototype installed in the reservoir named "El Negret", revealed (Table 1) that lower tilt angles not only provided better electrical performance but also a more regular module geometry. As the tilt angle of the FV array decreases, it is needed a shorter distance between row lines of PV panels to prevent interactive shadows. As a result, a more homogeneous module grid was obtained. Besides, low tilt angles significantly reduced the effects of wind uplift and drifting. Since wind forces play an important role in the structural behaviour of the system, the use of low tilt angles will improve the global performance of the system. Also, Table 1 shows the energy yield obtained from meteorological data and a global performance ratio of 0.75.

Table 1: Number of photovoltaic units and power installed depending on the tilt angle

\subsection{Orientation of the photovoltaic panels}

The layout shown in Figure 3 illustrates a particular case of a reservoir. First, the main axes of the cover (key directions of the floating modules) were determined taking into consideration the south cardinal and the direction of the reservoir slopes.

Figure 3: Cover configuration for a particular case study

The reservoir shown in Figure 3 has a rather rectangular geometry; moreover, the main longitudinal axes of the reservoir are aligned with the cardinal directions, so the solar panels faced south. However, such configuration will not be suitable for other sites where the slope's alignment of the reservoir does not fit the south orientation. Therefore, in such cases, the PV panels will be installed with higher deviations from the south direction since the directions of the reservoir slopes will always prevail over power production to achieve a good coupling of the whole platform inside the reservoir. Therefore, the successive rows of PV panels uniformly lean above the slope as the water level of the reservoir decreases without introducing biaxial forces and torsion stresses between modules.

Table 2: Power loss vs. azimuth rotation

As a result, there would be reservoirs where the main alignments of the platforms are no directly orientated to south. However, Table 2 compares the global irradiation expressed in equivalent sun hours of the system for a tilt angle of $10^{\circ}$, latitude of $38^{\circ}$ (prototype reservoir conditions) and azimuth rotation between 0 and $60^{\circ}$. As can be seen, azimuth variations are not relevant when using low tilt angles since the losses of irradiation are not significant. 


\section{DESCRIPTION OF THE SYSTEM}

The cover consists of a floating module, sized 2.35 x $2.35 \mathrm{~m}$, which is used as a frame for supporting a grid of units. Each module is joined to its adjacent ones with a metallic pin-anchorage. The platforms are fix-moored on the top of the reservoir.

The system can be applied to any water storage structure not exposed to heavy wave forces (ponds, tanks, reservoirs, lagoons, etc). However, the system described in this paper was designed to be used in agricultural reservoirs.

\subsection{Floating modules}

The pontoon is the key element of the system. It has to ensure the stability and buoyancy of the system and it is the basis of the photovoltaic plant. As shown in Figure 4, the module was designed to accommodate two standard solar panels with a tilt angle of $10^{\circ}$ and a $0.5 \mathrm{~m}$ access way located behind the upper side of the panels. It is shaped like a boat consisting of two hulls separated by an upper platform. The three main elements form a single square unit of $2.35 \mathrm{~m} \times 2.35 \mathrm{~m}$ and a height of $0.40 \mathrm{~m}$. After considering several alternatives, the material selected was medium density polyethylene made by rotomoulding.

Figure 4: Floating module

The two hulls have a trapezoidal section and a draft of $0.2 \mathrm{~m}$. They were placed longitudinally on the bottom of the pontoon. A slack and smooth contact between the module and the reservoir's geomembrane is needed to ensure excellent resistance to punctures [13]. The bottom of the trapezoidal hulls is thin and with rounded edges.

On the other hand, the technical requirements of the upper side of the pontoon are different from those of the bottom. The platform must resist several design loads, such as dead and live loads and wind uplift and drifting, so that it must be stiffer. The top side of the module consists of several rectangular gutters. As can be seen in Figure 4, these elements divide the platform into smaller units that improve the stiffness and the load bearing capacity of the system.

This configuration enables the installation of the horizontal steel frame which supports the solar panels. Also, the horizontal frame is a linking element that distributes the structural forces among the modules. Some additional gutters are used for the electrical wiring.

Finally, and in order to improve the stiffness and stability of the pontoon, both sides are attached by four vertical hollow cone-shaped columns. Such supports are symmetrically placed on the gutter's intersection.

On each side of the floating module there is a half-cylinder boss. The horizontal steel frame is placed vertically above the place where the half-cylinders rest.

These elements are built in during the manufacture of the module and their main role is to join adjacent modules and allow for the installation of the grid system. Thanks to this mechanism, the whole platform is able to transmit tension forces by means of the metallic rods, and compression forces through the contact of the plastic half-cylinders. 
In this way, downward rotation is controlled on the vertical plane. However, it is free to rotate upwards because the contact between successive half-cylinders tends to separate.

The aforementioned design features provide a better coupling of the system in singular areas of the reservoir such as the bottom and the internal walls.

Point loads on the platform may cause overlapping between adjacent horizontal halfcylinder bosses. To prevent such negative effect, vertical bosses are placed at the ends of the horizontal bosses thus limiting differential settlement.

The floating module described meets the design requirements. It is a safe, hollow and airtight element which can be made by the rotational molding technique.

\subsection{Joints between floating modules}

As previously mentioned, the cover layout is formed by a grid of modules joined together by means of metallic rods. The mechanism consists of a pinned joint that enables both the transmission of horizontal forces and vertical rotations, and allows the fitting of the cover to the geometry of the reservoir.

\subsection{Elastic joints}

The elastic joints enable the opening of the cover. In this way, the system can easily adapt to varying reservoir water levels. When the reservoir is empty, the longitudinal slope is longer than the surface of the full reservoir. To solve this problem, a number of elastic joints are placed along the main axes of the reservoir.

In the case of full reservoir, the elastic joints remain closed and the system practically covers the entire water surface. However, when the reservoir is empty, the elastic joints are completely opened and the system covers the internal walls of the reservoir. The grid of modules can adjust to any situation between these two extremes.

The opening mechanism is almost symmetrical to the main longitudinal axis of the reservoir. However, its installation and its mechanical and geometrical design will depend on the particular features of the site.

The modules situated at the outer cover perimeter are rigidly fixed to the top of the reservoir as follows.

\subsection{Rigid anchorages}

A rigid support along the perimeter of the reservoir is needed to withstand the dead loads acting on the reservoir slopes and the lateral forces caused by wind and waves. The anchorage system designed is made up of a pile foundation, a pile cap and a continuous perimeter floor.

The piles are placed at spaced intervals all around the reservoir's perimeter.

\section{DIGITAL AND REAL SCALE PROTOTYPE}

During the engineering design phase, several numerical and digital models were developed (further details on reference [12]). After the conceptual design, a real scale prototype was implemented in "El Negret" reservoir (Alicante) in order to check the real performance of the system, assembling process and power characterization. 


\subsection{Numerical and digital models}

The numerical models served to check the structural behaviour, buoyancy, mechanical interferences and energy gain of the system. The next step consisted in determining the engineering specifications of the components for further drawing and design [12].

Conventional methods and computational techniques were used to check the elements of the system. Digital models of the system were also developed as can be seen in Figure 5.

Figure 5: Digital model visualization

The finite element method (FEM) was a key tool used in the design of the floating module. The shape complexity of the module led us to combine Computer Aided Design (CAD) and FEM. The pontoon is made of medium density polyethylene (MDPE). Firstly, Figure 6 shows the four previous models modelled and analysed to withstand the forces of the system. The main loads acting on the system are summarized below: dead loads, photovoltaic panels, maintenance live loads, wind pressure and buoyancy forces.

Figure 6: Previous models of the floating module

Secondly, the specific design issues of rotomoulding together with the mechanical feedback gained with the four previous models enabled the conception of the pontoon consisting on two basic elements (Figure 7): a MDPE floating module and a horizontal steel frame supporting the PV array and loads due to weather conditions. A rigorous analysis of the structural response of the pontoon was carried out with different thicknesses (3-8 $\mathrm{mm}$ ) to assess the performance of the pontoon [12, 14].

According to plastic design [16, 17], a non-linear structural approach is performed since: i) Plastic materials exhibit a non-linear behaviour even at small strain values. Additionally, time and temperature enhance such effect, ii) MDPE undergoes significant geometric changes under load. So, changing the shape of the structure changes its stiffness. Therefore, the analytical approach must fit the geometric characteristics of the model, iii) The combined analysis of the plastic module and the metallic frame requires the mechanical interaction of two materials with different rheological behaviour.

The thorough parametric study determined a minimum thickness of $4 \mathrm{~mm}$ to meet the strength and deformation plastic conditions [18]. Meanwhile, the rigid frame is made from cold-formed steel profiles with UF-60x3 sections.

Figure 7: FEM Modelling (Plastic module + metallic frame)

\subsection{Real prototype}

Around 7\% of the water surface of the reservoir named "El Negret" (Figure 8) was used as a real scale prototype in order to check the behaviour of the system and make the appropriate technical and experimental changes.

The reservoir is located in Agost, a town near Alicante (East of Spain). The earth reservoir was covered with a high density polyethylene (HDPE) geomembrane. The 
reservoir has a slope section of 2.8 Horizontal/1.00 Vertical, maximum slope height of 5 $\mathrm{m}$ and maximum water storage capacity of $20,000 \mathrm{~m}^{3}$.

The prototype was installed in August 2009 and up to now its global performance has been highly satisfactory. For a peak power of $22.27 \mathrm{kWp}$ the yearly energy yield was $28,349 \mathrm{kWh}$ which corresponds to a performance ratio of $71.45 \%$.

The in-situ performance of the system has served to verify the feasibility of the solution as well as the following issues:

- Buoyancy conditions and free-draft measures under different load conditions.

- Efficient support of the modules on the reservoir slope, particularly at critical design points (vertex lines between planes).

- Mechanical behaviour of the system.

- Testing of different elastic joints in order to properly define loaddisplacement requirements.

- Cost estimation and assembling process.

Figure 8: Real model

\section{ECONOMIC VIABILITY}

The experience served to estimate the real cost of the elements of the system. The figures in Table 3 are an illustration of the economic viability of a $100 \mathrm{kWp}$ system.

Table 3: Estimated cost

The cost of the system is about 30 percent higher than that of a conventional gridconnected PV installation.

With the operation costs showed in Table 4, the profitability index obtained is 9.86\%.

Table 4: Operation costs

Also a financial evaluation has been carried out considering a loan (10 years, 4.5\%) for $80 \%$ of the investment, and an inflation index of 3\% (Table 5 and Figure 9).

Table 5: Financial evaluation

The Net Present Value (NPV) at $5 \%$ is $149,179 €$ and the Internal Rate of Return (IRR) $12.65 \%$. Although, logically, the system is less profitable than a conventional grid- 
connected PV installation, it keeps being profitable, even without quantifying the water savings.

Figure 9: Cumulative Net Cash Flows

\section{FINAL REMARK}

At the time the prototype was developed, the Spanish government guaranteed a revenue of $0.29 \mathrm{Euro} / \mathrm{kWh}$ for 25 years, but later on bonus policy was eliminated. However, due to the continuous increase of electricity prices and declining prices of PV modules, the self-consumption is presented as an option increasingly promising for our system. In fact, we are focusign our latest research in this direction, although Spanish law does not regulate yet the self-consumption completely.

\section{CONCLUSIONS}

The system is technically feasible and economically viable. In the near future, the surface of the reservoir will be totally covered with the floating system. The photovoltaic plant will become a source of income for the reservoir's owners. Additionally the system will help reduce water losses due to evaporation.

On the other hand, the system also contributes to more sustainable land management practices since a pre-existing water storage structure is used to install a photovoltaic plant instead of having to change the use of agricultural lands.

The Photovoltaic Floating Cover System (PFCS) described in this paper can be an efficient solution to certain agro-energetic policies and issues and to the need for water efficiency tools in the agricultural industry.

\section{ACKNOWLEDGEMENTS}

We would like to thank CELEMIN ENERGY S.L. for the confidence placed in our research group.

The system described in this text is under patent process [18].

The English revision of this paper was funded by the Universidad Politécnica de Valencia, Spain.

\section{REFERENCES}

[1] Bengoechea JM, Pérez Cobos J, Pérez Parra J, López Segura JG. Evaluación de las pérdidas de agua de riego en el Campo de Dalías, Almería. Symposium sobre el agua en Andalucía. Córdoba, 1991.

[2] Martínez Álvarez V, González-Real MM, Baille A, Maestre Valero FJ, Gallego Elvira B. Regional Assessment of Evaporation from Agricultural Irrigation Reservoirs in a Semiarid Climate. Agricultural Water Management 2008; 95: 1056-1066. 
[3] Craig I, Green A, Scobie M, Schmidt E. Controlling Evaporation Loss from Water Storages. NCEA Publication No 1000580/1. Queensland, 207 pp. 2005

[4] Gökbulak F, Özhan S. Water loss through evaporation from water surfaces of lakes and reservoirs in Turkey. E-Water: Official publication of the European Water Association. EWA, 2006.

[5] Morton FI. Evaporation research- a critical review and its lessons for the environmental sciencies. Crit Rev Environ Sci Technol 1994, 24: 237-280.

[6] Stanhill G. Is the Class-A evaporation pan still the most practical and accurate meteorological method for determining irrigation water requirements?. Agric For Meteorol 2002, 112:233-236.

[7] Hudson N.W. Soil and water conservation in semiarid regions. FAO Land and Water Conservation Service, Rome, 1987.

[8] Brown J.A.H. The potential for reducing open water evaporation losses: a review. Proceedings of the Hydrology and Water Resources Symposium, ANU, Camberra, Australia, 1988, pp 108-115.

[9] UNE 104426: Construcción de balsas cubiertas impermeabilizadas con geomembranas sintéticas. AENOR, 2008.

[10] Levy M. Preserving Our Water Resources. Civil Engineering-ASCE 2010, 80, 6267.

[11] Levy M. Saving the Blue Planet. In: Proceedings of the IASS Symposium on Evolution and Trends Analysis and Construction of Shell and Spatial Structures. Valencia, Domingo \& Lázaro Eds., UPV, 2009.

[12] Redón Santafé, M. Diseño de un Sistema de Cubierta Flotante Fotovoltaica para Balsas de Riego. Tesis Doctoral. Universidad Politécnica de Valencia, 2011.

[13] Koerner R.M. Designing with geosynthetics. Pearson Prentice Hall, New Jersey, 2005.

[14] Redón M., Ferrer C., Ferrer C.M., Ferran J.J., Torregrosa J.B., Sanchez F.J. Photovoltaic Floating Cover system for reservoirs. In: Proceedings of the IABSE-IASS Symposium Taller, Longer, Lighter, London, Nethercot \& Pellegrino Eds, 2011.

[15] Crawford R.J. Plastics Engineering. Butterworth-Heinemann, Oxford, 1998.

[16] Ehrenstein G.W. Polymeric Materials. Carl Hanser Verlag, Munich, 2001.

[17] Mascarenhas W. N., Ahrens C.H., Ogliari, A. Design criteria and safety factors for plastic components design. Materials and Design 2004; 25-3, 257-261.

[18] Floating Photovoltaic Cover System. Patent Publication Number: WO/2010/100291. 
Table 1: Number of photovoltaic units and power installed depending on the tilt angle

\begin{tabular}{|c|c|c|c|c|c|}
\hline $\begin{array}{c}\text { Tilt } \\
\text { angle }\end{array}$ & $\begin{array}{c}\text { Number } \\
\text { of floating } \\
\text { modules } \\
\text { ( } 2 \text { PV } \\
\text { panels) }\end{array}$ & $\begin{array}{l}\text { Floating } \\
\text { module size } \\
\text { (Width x } \\
\text { length) } \\
\text { (m) }\end{array}$ & $\begin{array}{l}\text { Peak Power } \\
\text { installation } \\
\quad(\mathbf{k W p})\end{array}$ & $\begin{array}{c}\text { Peak } \\
\text { Power density } \\
\left(\mathrm{Wp} / \mathbf{m}^{2}\right)\end{array}$ & $\begin{array}{c}\text { Energy yield } \\
\text { (kWh/m² } \\
\text { year) }\end{array}$ \\
\hline $30^{\circ}$ & 652 & $3.40 \times 2.00$ & 260.8 & 55.46 & 82.49 \\
\hline $15^{\circ}$ & 787 & $2.20 \times 2.55$ & 314.8 & 65.55 & 104.27 \\
\hline $10^{\circ}$ & 908 & $2.20 \times 2.20$ & 363.2 & 74.16 & 114.89 \\
\hline
\end{tabular}


Table 2: Power loss vs. azimuth rotation

\begin{tabular}{|c|c|c|}
\hline $\begin{array}{c}\text { Azimuth } \\
\text { rotation }\end{array}$ & $\begin{array}{c}\text { Peak Sun- } \\
\text { Hours } \\
\text { (PSH) }\end{array}$ & $\begin{array}{c}\text { Losses } \\
\text { regarding 0 } \\
\text { azimuth }\end{array}$ \\
\hline $0^{\circ}$ & 1,800 & - \\
\hline $10^{\circ}$ & 1,800 & $0.00 \%$ \\
\hline $20^{\circ}$ & 1,790 & $-0.56 \%$ \\
\hline $30^{\circ}$ & 1,780 & $-0.56 \%$ \\
\hline $40^{\circ}$ & 1,770 & $-0.56 \%$ \\
\hline $50^{\circ}$ & 1,750 & $-1.13 \%$ \\
\hline $60^{\circ}$ & 1,730 & $-1.14 \%$ \\
\hline
\end{tabular}


Table 3: Estimated cost

\begin{tabular}{|l|r|r|}
\hline Concept & & Cost (€) \\
\hline Platform & & \\
\hline Pontoons & & 40755 \\
\hline Pontoons transport & & 1045 \\
\hline Structure & & 19855 \\
\hline Tensors & & 3135 \\
\hline Screws and rivets & & 564 \\
\hline Assembly & Total platform & 69534 \\
\hline & & \\
\hline Foundations and elastic joints & & 7000 \\
\hline Pilot foundation & & 6000 \\
\hline Elastic joints & & 82534 \\
\hline & Total covering & \\
\hline “Conventional” costs & & 19461 \\
\hline Inverters & & 140000 \\
\hline Photovoltaic panels & & 19000 \\
\hline Wiring & & 2000 \\
\hline Monitoring & & 7000 \\
\hline Security & & 8300 \\
\hline Engineering & & 2000 \\
\hline Health and safety on site & & 800 \\
\hline Quality control & & 198561 \\
\hline & & 340126 \\
\hline Overheads (15\%) & & \\
\hline Industrial profit (6\%) & & \\
\hline Total costs & & \\
\hline
\end{tabular}


Table 4: Operation costs

Energy production $135000 \mathrm{kWh}$

Gross income $\quad 39150 € /$ year $(0.29 € / \mathrm{kWh})$

\begin{tabular}{l|l}
\hline Leasing & $1296 € /$ year
\end{tabular}

Maintenance $\quad 4320 € /$ year 


\begin{tabular}{|c|c|c|c|c|c|c|c|c|c|c|c|c|c|c|c|c|c|c|c|c|c|c|c|c|c|c|}
\hline 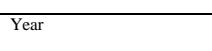 & 0 & 1 & 2 & 3 & 4 & 5 & 6 & 7 & 8 & 9 & 10 & 11 & 12 & 13 & 14 & 15 & 16 & 17 & 18 & 19 & 20 & 21 & 22 & 23 & 24 & 25 \\
\hline Revenues from energy sales & & 39.852 & 40.743 & 41.654 & 42.586 & 43.432 & 44.295 & 45.176 & 46.074 & 46.989 & 47.923 & 48.876 & 49.847 & 50.838 & 51.848 & 52.879 & 53.930 & 55.002 & 56.095 & 57.210 & 58.347 & 59.506 & 60.689 & 61.895 & 63.125 & 64.380 \\
\hline Insurances & & 1.469 & 1.513 & 1.558 & 1.605 & 1.653 & 1.703 & 1.754 & 1.807 & 1.861 & 1.917 & 1.974 & 2.033 & 2.094 & 2.157 & 2.222 & 2.289 & 2.357 & 2.428 & 2.501 & 2.576 & 2.653 & 2.733 & 2.815 & 2.899 & 2.986 \\
\hline $\begin{array}{l}\text { Maintenance } \\
\end{array}$ & & 4.320 & 4.450 & 4.583 & 4.721 & 4.862 & 5.008 & 5.158 & 5.313 & 5.472 & 5.637 & 5.806 & 5.980 & 6.159 & 6.344 & 6.534 & 6.730 & 6.932 & 7.140 & 7.355 & 7.575 & 7.802 & 8.036 & 8.278 & 8.526 & 8.782 \\
\hline Leasing & & 1.296 & 1.335 & 1.375 & 1.416 & 1.459 & 1.502 & 1.547 & 1.594 & 1.642 & 1.691 & 1.742 & 1.794 & 1.848 & 1.903 & 1.960 & 2.019 & 2.080 & 2.142 & 2.206 & 2.273 & 2.341 & 2.411 & 2.483 & 2.558 & 2.635 \\
\hline Gross operating margin & & 32.767 & 33.446 & 34.138 & 34.844 & 35.458 & 36.082 & 36.716 & 37.360 & 38.014 & 38.679 & 39.354 & 40.040 & 40.736 & 41.444 & 42.162 & 42.892 & 43.632 & 44.384 & 45.148 & 45.923 & 46.710 & 47.509 & 48.320 & 49.142 & 49.978 \\
\hline Depreciation expenses & & 34.013 & 34.013 & 34.013 & 34.013 & 34.013 & 34.013 & 34.013 & 34.013 & 34.013 & 34.013 & & & & & & & & & & & & & & & \\
\hline Financial expenses & & 12.245 & 11.248 & 10.207 & 9.119 & 7.982 & 6.793 & 5.552 & 4.254 & 2.898 & 1.481 & & & & & & & & & & & & & & & \\
\hline Profit before taxes & & -13.490 & -11.815 & -10.082 & -8.287 & -6.536 & -4.724 & -2.848 & -906 & 1.104 & 3.186 & 39.354 & 40.040 & 40.736 & 41.444 & 42.162 & 42.892 & 43.632 & 44.384 & 45.148 & 45.923 & 46.710 & 47.509 & 48.320 & 49.142 & 49.978 \\
\hline Taxes $(25 \%)$ & & 0 & 0 & 0 & 0 & 0 & 0 & 0 & 0 & 276 & 796 & 9.839 & 10.010 & 10.184 & 10.361 & 10.541 & 10.723 & 10.908 & 11.096 & 11.287 & 11.481 & 11.678 & 11.877 & 12.080 & 12.286 & 12.494 \\
\hline Profit after taxes & & -13.490 & -11.815 & -10.082 & -8.287 & -6.536 & -4.724 & -2.848 & -906 & 828 & 2.389 & 29.516 & 30.030 & 30.552 & 31.083 & 31.622 & 32.169 & 32.724 & 33.288 & 33.861 & 34.442 & 35.033 & 35.632 & 36.240 & 36.857 & 37.483 \\
\hline Payment of loan principal & & 22.143 & 23.140 & 24,181 & 25.269 & 26.406 & 27.595 & 28.836 & 30.134 & 31.490 & 32.907 & & & & & & & & & & & & & & & \\
\hline Net cash flows & -68.025 & -1.621 & -942 & -250 & 456 & 1.070 & 1.694 & 2.328 & 2.972 & 3.351 & 3.495 & 29.516 & 30.030 & 30.552 & 31.083 & 31.622 & 32.169 & 32.724 & 33.288 & 33.861 & 34.442 & 35.033 & 35.632 & 36.240 & 36.857 & 37.483 \\
\hline Cumulative Net Cahs Flows & -68.025 & -69.646 & -70.588 & -70.838 & -70.382 & -69.312 & -67.618 & -65.290 & -62.317 & -58.967 & -55.472 & -25.956 & 4.074 & 34.626 & 65.709 & 97.330 & 129.499 & 162.223 & 195.511 & 229.372 & 263.814 & 298.847 & 334.478 & 370.718 & 407.575 & 445.058 \\
\hline
\end{tabular}

Table 5: Financial evaluation 